OPEN ACCESS

Edited by:

Jin-Gui Chen,

Oak Ridge National Laboratory,

United States

Reviewed by:

Viktor Zarsky

Charles University, Czechia

Jin Suk Lee,

Concordia University, Canada

Hemayet Ullah,

Howard University, United States

*Correspondence:

Yajun Gao

yajungao@nwsuaf.edu.cn

Alan M. Jones

alan_jones@unc.edu

Specialty section:

This article was submitted to

Plant Cell Biology,

a section of the journal

Frontiers in Plant Science

Received: 11 February 2017

Accepted: 26 May 2017

Published: 13 June 2017

Citation:

Liang Y, Gao Y and Jones AM (2017)

Extra Large G-Protein Interactome

Reveals Multiple Stress Response

Function and Partner-Dependent XLG

Subcellular Localization.

Front. Plant Sci. 8:1015.

doi: $10.3389 /$ fpls.2017.01015

\section{Extra Large G-Protein Interactome Reveals Multiple Stress Response Function and Partner-Dependent XLG Subcellular Localization}

\author{
Ying Liang ${ }^{1,2}$, Yajun Gao ${ }^{1 *}$ and Alan M. Jones ${ }^{2,3 *}$ \\ ${ }^{1}$ College of Natural Resources and Environment, Northwest A\&F University, Xianyang, China, ${ }^{2}$ Department of Biology \\ University of North Carolina at Chapel Hill, Chapel Hill, NC, United States, ${ }^{3}$ Department of Pharmacology, University of North \\ Carolina at Chapel Hill, Chapel Hill, NC, United States
}

The three-member family of Arabidopsis extra-large G proteins (XLG1-3) defines the prototype of an atypical $\mathrm{G} \alpha$ subunit in the heterotrimeric $\mathrm{G}$ protein complex. Recent evidence indicate that XLG subunits operate along with its G $\beta \gamma$ dimer in root morphology, stress responsiveness, and cytokinin induced development, however downstream targets of activated XLG proteins in the stress pathways are rarely known. To assemble a set of candidate XLG-targeted proteins, a yeast two-hybrid complementation-based screen was performed using XLG protein baits to query interactions between XLG and partner protein found in glucose-treated seedlings, roots, and Arabidopsis cells in culture. Seventy two interactors were identified and $>60 \%$ of a test set displayed in vivo interaction with XLG proteins. Gene co-expression analysis shows that $>70 \%$ of the interactors are positively correlated with the corresponding XLG partners. Gene Ontology enrichment for all the candidates indicates stress responses and posits a molecular mechanism involving a specific set of transcription factor partners to XLG. Genes encoding two of these transcription factors, SZF1 and 2, require XLG proteins for full $\mathrm{NaCl}$-induced expression. The subcellular localization of the XLG proteins in the nucleus, endosome, and plasma membrane is dependent on the specific interacting partner.

Keywords: Arabidopsis, extra-large G protein, XLG protein interactome, salt stress, SZF, yeast two hybrid, NaCl

\section{INTRODUCTION}

In animals, the heterotrimeric $G$ protein complex consists of $G \alpha, G \beta$, and $G \gamma$ subunits and is tethered to the cytoplasmic side of the plasma membrane nestled with 7 transmembrane (Hamm, 1998; Oldham and Hamm, 2008). G protein coupled receptors (GPCR). GPCRs receive extracellular signals and then activate the G protein signaling pathway by catalyzing GDP removal from the G $\alpha$ subunit allowing GTP binding and subsequent release of the G $\beta \gamma$ dimer (Wettschureck, 2005; Li et al., 2007; Oldham and Hamm, 2008). The G $\alpha$ subunit has an intrinsic GTP hydrolysis rate that returns the heterotrimeric complex to its basal (resting) state. Regulator of G Signaling (RGS) proteins accelerate GTP hydrolysis. The human genome encodes $23 \mathrm{G} \alpha, 5 \mathrm{G} \beta$, and $12 \mathrm{G} \gamma$ subunits, $\sim 850$ GPCRs, and $\sim 40$ RGS proteins. In Arabidopsis, the heterotrimeric $\mathrm{G}$ protein complex consist 
of one canonical alpha subunit (AtGPA1), one beta subunit (AGB1), one of three gamma subunits (AGG1, 2, and 3), at least one subunit of Regulator of G Signaling protein (AtRGS1), and one of three atypical Extra-Large G proteins (XLG1, 2, and 3) (Pandey et al., 2006; Ding et al., 2008; Chakravorty et al., 2011; Urano et al., 2013, 2016; Wolfenstetter et al., 2015) in lieu of the canonical G subunit. In plants, the mechanism for activation is different than in animals; the $\mathrm{G} \alpha$ subunit self-activates without a GPCR and instead is kept in the basal state by a 7 transmembrane RGS protein (Urano et al., 2012, 2013).

The presence of atypical XLGs makes G protein signaling in plants unique. The primary sequence conservation of the Cterminal $\mathrm{G} \alpha$ domain of the three XLG proteins compared to the canonical $\mathrm{G} \alpha$ are $26.1,23.2$, and $28.5 \%$ identities for XLG1 ${ }^{446-888}$, $\mathrm{XLG}^{435-861}$, and XLG3 $3^{396-848}$, respectively (Ding et al., 2008; Chakravorty et al., 2015; Urano et al., 2016). The G $\alpha$ domain of XLGs is structurally similar to AtGPA1 containing three of five G-box motifs that are critical for binding the guanine nucleotide. The N-terminal region of XLGs contains a nuclear localization signal (NLS) and at least XLG3 in this family encodes a functional nuclear export signal (NES) (Chakravorty et al., 2015). Whether or not XLGs bind guanine nucleotides is unclear but the evidence to date indicate that if they do, the mode is different from the canonical G $\alpha$ subunit (Lee and Assmann, 1999; Heo et al., 2012). In vitro studies indicate that XLGs bind the $\mathrm{G} \beta \gamma$ dimer but do so unlike the canonical $\mathrm{G} \alpha$ subunit (Maruta et al., 2015) and possibly do so independently of nucleotide binding (Urano et al., 2016). Finally, there is uncertainty in the literature about the subcellular location of XLGs. Ding et al. (2008) found fluorescence localized to the nucleus when XLGs-GFP or the N-terminal XLG-GFP proteins were transiently overexpressed in Vicia faba guard cells, while Maruta et al. (2015) found that the XLG proteins are located in both nucleus and plasma membrane (XLG1-GFP only displayed a plasma membrane signal) in the Arabidopsis stable transgenic lines with GFP-XLGs, however when in complex with the G $\beta \gamma$ dimer, XLGs are only located on the plasma membrane (Maruta et al., 2015). Chakravorty et al. (2015) confirmed the interaction of the XLG with the G $\beta \gamma$ dimer at the plasma membrane but also showed that when the XLG-GFP protein was not obligated to partner with the G $\beta \gamma$ dimer, fluorescence was noted in the nucleus. These findings raise the possibility that XLG subcellular localization is conditional.

It is established that $G$ proteins are involved in various stress responses. AtRGS1 is a glucose sensor (Grigston et al., 2008), but is also involved in regulating certain stress responses. For example, the null mutants of AtRGS1 are more resistant to salt stress (Colaneri et al., 2014). The AGB1 mutants are hypersensitive to salt stress (Yu and Assmann, 2015), ER stress, and glucose stress (Pandey et al., 2006). Similarly to the AGB1 mutants, the XLG1/2/3 triple mutant is hypersensitive to salt, tunicamycin, and $\mathrm{D}$-glucose in post germination development (Chakravorty et al., 2015; Maruta et al., 2015; Urano et al., 2016). XLG proteins are involved in stress responses (Urano et al., 2016), however, the mechanism is unclear.

Few protein partners to XLGs are known. Heo et al. (2012) performed a yeast two hybrid (Y2H) screen for XLG2 and found that XLG2 interacts with the nuclear protein RTV1 (related to vernalization 1). Wang et al. (2017) identified two plant U-box E3 ligases (PUB2 and 4) that interact with XLG proteins. The double pub1/2 mutant shares developmental phenotypes to the $x \lg 1 / 2 / 3$ triple mutant. These two groups did not report any other XLG interactor.

In order to elucidate the mechanism for XLG-mediated stress responsiveness and development, we must first assemble the set of proteins operating in the associated pathways. Here, we report a set of proteins identified in a Y2H screen for XLG protein partners. A large proportion of the identified candidate XLG interactors are implicated in various stress responsive signaling pathways. Many of these are confirmed to interact with XLG in vivo. Analyses of the consequences of XLG-partner interaction revealed that the subcellular localization of the XLG protein is conditional on its binding partner, resolving the conflicting published data on XLG localization.

\section{MATERIALS AND METHODS}

\section{Yeast Two Hybrid Screening for the XLG Interactome}

The process of screening the interactome of XLGs using Y2H followed the Yeast Protocols Handbook by Clontech. Briefly, the full length XLGs were cloned into the pENTR/D-TOPO vector (Invitrogen), then recombined into the pAS2-1 GATEWAY vector (Criekinge and Beyaert, 1999). The bait vectors were transformed into Saccharomyces cerevisiae strain AH109 and autoactivation was tested in the triple dropout plates (-TrpHis-Ade) with the indicated proper amounts of 3-amino-1,2,4triazole (3-AT). The library plasmids were transformed into the Y187 strain according to the "Mate \& Plate ${ }^{\mathrm{TM}}$ " Library System User Manual from Clontech (http://www.clontech.com). All media and reagents were made as indicated by the manufacturer (Clontech). After mating, the culture was spread on dropout (DO) plates according to the autoactivation results as follows. For XLG1, the first screen was on quadruple DO (Try/Leu/His/Ade) plates with $10 \mathrm{mM} 3$-AT and subsequently screened on quadruple DO plates with $20 \mathrm{mM}$ 3-AT. For XLG2 and XLG3, transformants were spread on triple DO (Try/Leu/His) plates with $1 \mathrm{mM} \mathrm{3-AT}$ and subsequently screened on quadruple DO (-Try/Leu/His/Ade) plates with X-alpha-gal. Positive colonies further purified by spreading on new plates twice for confirmation and then cultured in -Leu liquid medium to rescue the plasmids. Plasmid DNA were amplified with primer GAL4-AD-Fw (AATACCACTACAATGGAT). Plasmids were restricted with enzymes HindIII, AvaI, and SmaI individually to eliminate duplicates before sequencing. The sequencing results were analyzed by BLAST in NCBI (https://www.ncbi.nlm.nih. gov/).

\section{Genetic Stocks}

The following T-DNA insertion mutants were used: agb1-2 (Ullah et al., 2003), rgs1-2 (Chen et al., 2003), gpa1-3 (Jones et al., 2003), $x \lg 1 x \lg 2 x \lg 3$ (Ding et al., 2008) which combines these alleles xlg1-1 (SAIL_760H08) (Ding et al., 2008), xlg2-2 (SALK_062645), xlg3-2 (SAIL_107656) (Ding et al., 2008), and $x \lg / g p a 1$ which combines the $x \lg 1-1, x \lg 2-1, x \lg 3-2$, and $g p a 1-3$ 
alleles above (Urano et al., 2016). The ATG number for the genes are At4g34460 (AGB1); At2g26300 (GPA1); At3g26090 (RGS1); At2g23460 (XLG1); At4g34390 (XLG2); At1g31930 (XLG3). The single mutants of szf1 (Salk_002993, Salk_141550) and szf2 (Salk_024800C, CS873730) were obtained from the Arabidopsis Biological Resource Center (ABRC, http://www.arabidopsis.org/) and made homozygous.

\section{BiFC}

BiFC was performed as described by Klopffleisch et al. (2011) and Tunc-Ozdemir et al. (2016). Briefly, pENTR clones of the genes of interest were subcloned into pCL113_JO (for N-terminal tagged cYFP) and the bait genes were subcloned into pCL112 and pBatLsYFP-C (for C-terminal tagged cYFP). A positive-transformation control [mitochondrial RFP marker; mt-rk obtained from the ABRC (CD3-991)] was used to distinguish gene silencing from lack of protein complementation. NLS-CFP were used as a nucleus marker for the subcellular localization. Leaf samples were imaged using a Zeiss LSM710 confocal laser scanning microscope equipped with an Apochromat X40 (NA 1.2) water immersion objective. YFP and RFP were excited by a 514-nm argon laser and a 560-nm diode laser, respectively, and their respective emissions were detected at 526-569 and 565-621 nm by a photomultiplier detector. The digital images were analyzed with Zen software (Zeiss). CFP was excited with a 458-nm argon laser and the emission was detected at $490 \mathrm{~nm}$.

\section{Culture of Arabidopsis and Salt Treatment}

Arabidopsis seeds were sterilized with $70 \%$ ethanol for $10 \mathrm{~min}$, 95\% ethanol for $10 \mathrm{~min}$ and sterilized water wash at least three times. Liquid culture of Arabidopsis was described by Grigston et al. (2008). Briefly, sterilized seeds were stratified at $4{ }^{\circ} \mathrm{C}$ in the dark for 3-4 days, and then transferred to 250-mL flasks with 100 $\mathrm{mL}^{1 / 4} \mathrm{MS}$ liquid medium with $1 \%$ sucrose at a density of about 50 seeds per flask. The seedlings were grown under constant dim light (35-50 $\left.\mathrm{\mu Em}^{-2} \mathrm{~s}^{-1}\right)$ shaking at $120 \mathrm{rpm}$ for 7 days. While performing the treatment, the seedlings were gently removed and transferred into new flasks with $1 / 4$ MS liquid medium plus the indicated concentrations of $\mathrm{NaCl}$. After treatment, seedlings were gently dried on tissue and wrapped in aluminum foil before flash freezing with liquid nitrogen. Samples were stored at $-80 \mathrm{C}$ until analyses.

\section{RNA Isolation, Reverse Transcription, and Real Time PCR}

Total RNA was isolated from seedlings treated with the indicated $\mathrm{NaCl}$ treatments were frozen in liquid nitrogen followed by homogenization in a mortar. RNA extraction was performed using an RNeasy Mini Kit (QIAGEN; Cat No: 74106) according to manufacturer's instructions. Residual genomic DNA was removed by treatment with RNase free DNase I (Thermo Fisher; Cat No. AM2222). First Strand cDNA was synthesized from 5 ug of total RNA using Thermo Scientific Maxima Reverse Transcriptase (Cat No: EP0741) according to the suppliers protocol using an anchored oligo (d) T primer mix. Real time PCR was performed using DNA Engine Opticon 2 System from MJ research and the comparative Ct-value (Threshold Cycle defined as the cycle number at which the fluorescence generated within a reaction crosses the threshold line) was measured with SYBR green (Invitrogen). The relative gene expression level was expressed as $2^{-\Delta \Delta \mathrm{Ct}}$ as described by Livak and Schmittgen (2001). Primers are provide in Supplementary Table S2. PCRprogram steps were: 94 degree $\mathrm{C}$ for $5 \mathrm{~min},\left[9^{\circ} \mathrm{C}\right.$ for $10 \mathrm{~s}, 62^{\circ} \mathrm{C}$ for $20 \mathrm{~s}, 72^{\circ} \mathrm{C}$ for $20 \mathrm{~s}$ ] 40 times followed by a dissociation curve measurement.

\section{Salt Stress Assay}

The growth medium was $1 / 4$ MS medium with $1 \%$ sucrose, 1 g/L 2-(N-morpholino) ethanesulfonic acid and $0.8 \%$ phytoagar (pH5.7) with $5 \mathrm{M} \mathrm{NaCl}$ stock added to make the indicated $\mathrm{NaCl}$ concentrations. The seeds on plates were kept at $4^{\circ} \mathrm{C}$ for 3 days in the dark and then the plates were transferred to constant light for 14 days.

\section{Protoplast Isolation and Transformation}

Protoplast transformation was performed as described (Yoo et al., 2007). Briefly, 5-week-old Arabidopsis plants grown under short days (8/16 h light/dark) were used for the protoplast isolation. After the transformation, protoplasts were incubated in 24-wellplates for 2 days and the samples were imaged as described above.

\section{RESULTS AND DISCUSSION}

\section{XLG Interactome}

Full length XLGs proteins were used as baits to screen for interacting proteins using the $\mathrm{Y} 2 \mathrm{H}$ assay. Tests for autoactivation by the baits indicated that XLG1 auto-activates however, optimization with 3-AT (3-amino-1,2,4-triazole) reduced auto-activation to a level that enabled successful screening (Supplementary Figure S1). XLG2 and XLG3 did not auto-activate.

Three Arabidopsis cDNA libraries designated GLUC, ROOT, and SAL (Klopffleisch et al., 2011) were screened using XLG baits. Briefly, the GLUC library was created from glucose treated, 7-day old Arabidopsis thaliana Col 0 seedlings grown in liquid culture ( $1 \%$ sucrose 7 days, no sucrose 2 days, $6 \%$ glucose $3 \mathrm{~h}$ ), the ROOT library was created from 7-day-old roots, and the SAL library was created from $A$. thaliana suspension culture cells. The XLG2 bait was used only to screen the GLUC library. The primary candidate set (Supplementary Table S4) was culled of known Y2H artifacts (Venkatesan et al., 2009; Klopffleisch et al., 2011) and redundant entries to make a collection of 72 proteins of which 22 were found using XLG1, 3 were found using XLG2, and 49 were found using XLG3 baits. The full set of candidate XLG interacting proteins is provided in Table $\mathbf{1}$ with the corresponding confidence levels given by $P$-values. No single protein family was over represented and the set contained over $10 \%$ hypothetical proteins. We did not find the previously-reported XLG2 interactor nuclear protein RTV1 (Heo et al., 2012). While the previously-published PUB2 and 4 E3 ligases (Wang et al., 2017) where not found in this screen, the E3 ligase XBAT32 was found to interact with XLG1. XBAT32 is a RING-subtype whereas PUB2 and 4 are in the HECT 
TABLE 1 | Newly-discovered candidate XLG interacting proteins.

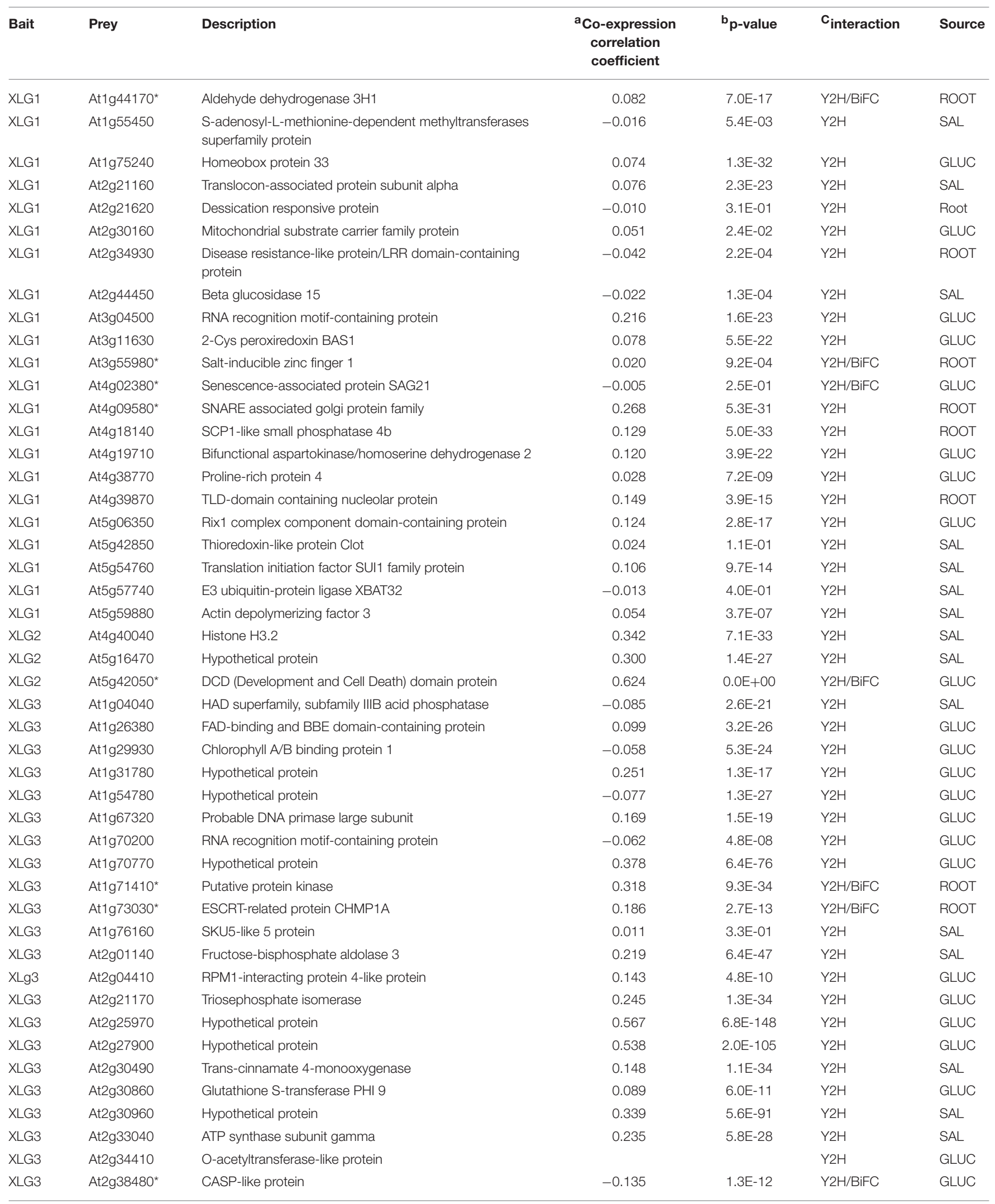


TABLE 1 | Continued

\begin{tabular}{|c|c|c|c|c|c|c|}
\hline Bait & Prey & Description & $\begin{array}{c}{ }^{a} \text { Co-expression } \\
\text { correlation } \\
\text { coefficient }\end{array}$ & ${ }^{b} p$-value & $\mathrm{C}_{\text {interaction }}$ & Source \\
\hline XLG3 & At2g40140* & Zinc finger CCCH domain-containing protein 29 & 0.137 & 1.1E-35 & Y2H/BiFC & GLUC \\
\hline XLG3 & At2g41430* & Dehydration-induced protein ERD15 & 0.162 & 2.0E-32 & $\mathrm{Y} 2 \mathrm{H}$ & GLUC \\
\hline XLG3 & At2g43620 & Chitinase family protein & 0.025 & 3.1E-04 & $\mathrm{Y} 2 \mathrm{H}$ & GLUC \\
\hline XLG3 & At3g02120 & Hydroxyproline-rich glycoprotein-like protein & 0.040 & 8.2E-04 & $\mathrm{Y} 2 \mathrm{H}$ & SAL \\
\hline XLG3 & At3g03780 & Methionine synthase 2 & 0.045 & 4.8E-04 & Y2H & GLUC \\
\hline XLG3 & At3g16420 & PYK10-binding protein 1 & 0.005 & 3.7E-01 & $\mathrm{Y} 2 \mathrm{H}$ & GLUC \\
\hline XLG3 & At3g19640* & Magnesium transporter MRS2-3 & 0.516 & $1.2 \mathrm{E}-135$ & Y2H/BiFC & GLUC \\
\hline XLG3 & At3g19820 & Delta(24)-sterol reductase & 0.119 & 1.7E-26 & Y2H & GLUC \\
\hline XLG3 & At3g26520* & Aquaporin TIP1-2 & -0.068 & $9.5 \mathrm{E}-16$ & $\mathrm{Y} 2 \mathrm{H}$ & ROOT \\
\hline XLG3 & At3g27090* & DCD (Development and Cell Death) domain protein & 0.168 & 1.4E-11 & Y2H/BiFC & SAL \\
\hline XLG3 & At3g42050* & V-type proton ATPase subunit H & 0.267 & $2.1 \mathrm{E}-21$ & $\mathrm{Y} 2 \mathrm{H}$ & GLUC \\
\hline XLG3 & At3g44100 & Hypothetical protein & 0.274 & 1.1E-31 & Y2H & SAL \\
\hline XLG3 & At3g60210* & GroES-like family protein & -0.049 & 3.8E-02 & Y2H & ROOT \\
\hline XLG3 & At3g60750 & Transketolase & -0.050 & $6.2 \mathrm{E}-05$ & $\mathrm{Y} 2 \mathrm{H}$ & GLUC \\
\hline XLG3 & At4g14520 & DNA-directed RNA polymerase II-like protein & & & $\mathrm{Y} 2 \mathrm{H}$ & GLUC \\
\hline XLG3 & At4g15910* & DROUGHt-INDUCED 21 & 0.128 & 4.7E-70 & Y2H & SAL \\
\hline XLG3 & At4g28610* & Phosphate starvation response 1 protein & 0.483 & $1.5 \mathrm{E}-83$ & $\mathrm{Y} 2 \mathrm{H}$ & GLUC \\
\hline XLG3 & At4g37180 & myb family transcription factor & 0.273 & 2.3E-62 & $\mathrm{Y} 2 \mathrm{H}$ & GLUC \\
\hline XLG3 & At5g06310 & protection of telomeres $1 \mathrm{~b}$ & & & $\mathrm{Y} 2 \mathrm{H}$ & GLUC \\
\hline XLG3 & At5g17670 & Hydrolase-like protein & -0.126 & $1.2 \mathrm{E}-23$ & Y2H & GLUC \\
\hline XLG3 & At5g17920 & \multicolumn{3}{|c|}{ 5-methyltetrahydropteroyltriglutamate-homocysteine methyltransferase } & $\mathrm{Y} 2 \mathrm{H}$ & GLUC \\
\hline XLG3 & At5g28740 & tetratricopeptide repeat domain-containing protein & 0.539 & $1.1 \mathrm{E}-145$ & $\mathrm{Y} 2 \mathrm{H}$ & SAL \\
\hline XLG3 & At5g44340* & Tubulin beta chain 4 & 0.046 & 1.8E-02 & $\mathrm{Y} 2 \mathrm{H}$ & GLUC \\
\hline XLG3 & At5g45760 & Transducin/WD40 domain-containing protein & 0.402 & $6.9 \mathrm{E}-71$ & $\mathrm{Y} 2 \mathrm{H}$ & GLUC \\
\hline XLG3 & At5g66240* & Transducin family protein / WD-40 repeat family protein & 0.516 & 1.0E-97 & Y2H/BiFC & GLUC \\
\hline
\end{tabular}

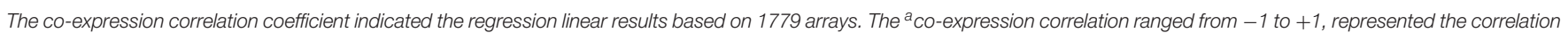
direction, closer to +1 , the more positive relation. The ${ }^{b} p$-value indicated the strength of the correlation.

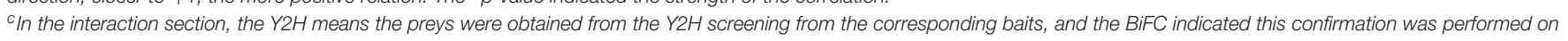
both XLG1 and XLG3 full length. The prey proteins used for the BiFC assay marked with *.

subfamily of E3 ligases. XBAT2 is also found in the G protein interactome (Klopffleisch et al., 2011).

\section{GO Analysis Indicates Enrichment in Stress Response}

Urano et al. (2016) quantitated 30 phenotypic traits of the $x \lg 1,2,3$ triple mutant, including all the known agb1 mutant phenotypes, and concluded that XLG proteins are important for many physiologies and development. The single mutant alleles of the three $X L G$ genes have wild type hypocotyl lengths and primary root lengths (Ding et al., 2008), and showed no differences in response to salt, tunicamycin and D-glucose in post-germination development compared to wildtype seedlings (Chakravorty et al., 2015). Only the single mutants of XLG2 have altered plant immunity responses (Maruta et al., 2015). Therefore, we analyzed for predicted functions of the XLG interactors.

Gene Ontogeny (GO) analysis was performed for the candidate set of interactors using BiNGO in cytoscape (Maere et al., 2005). For the "biological_process" analysis, the cutoff $p$ value was set to 0.05. As shown in Figure 1A, the main GO enrichment for all the interactors were stress and abiotic stimuli. These results were consistent with the G protein interactors enriched in biotic/abiotic stresses, developmental processes and cell organization, and biogenesis (Klopffleisch et al., 2011). GO analysis of the current set of interactors also revealed proteins involved in amino acids biosynthesis and metabolic process, including methionine, homocysteine, sulfur amino acid and aspartate family amino acid (Supplementary Table S1).

\section{Correlation of Gene Expression Supports the Reliability of the XLG Interactome}

Correlated expression is a Predictor of co-functionality of genes in common pathways and processes (Bhardwaj and Lu, 2009). Protein partners, in order to functionally interact, must be expressed in the same cells, compartments, and induced or repressed by the same conditions. Therefore, we analyzed coexpression of corresponding genes between the 72 pairs of interactors and corresponding XLG genes using the online software CressExpress (http://cressexpress.org/). CressExpress performs linear regression using expression values harvested from publicly-available microarray data. We used version 3 

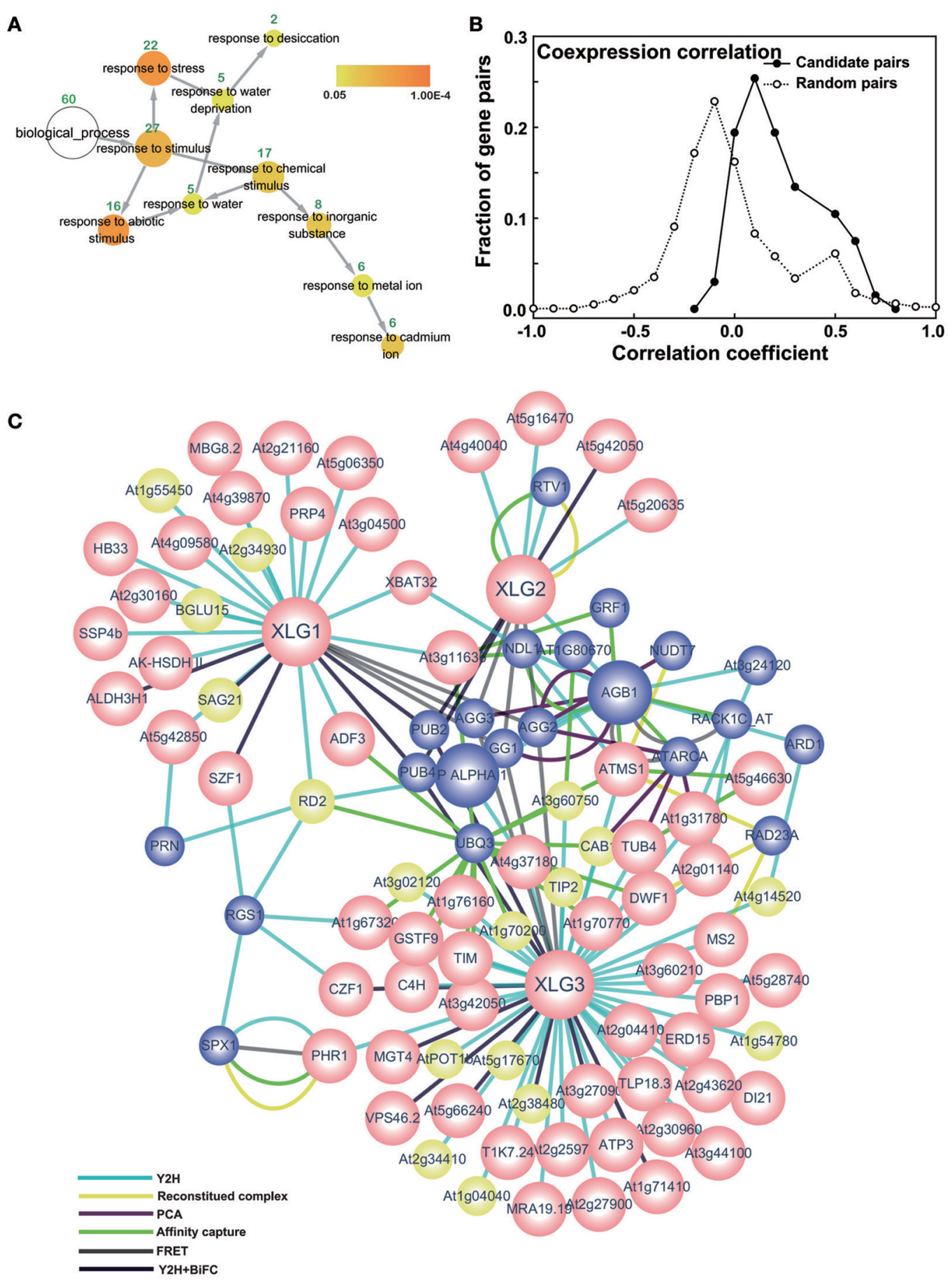

FIGURE 1 | Core XLG interactome. (A) GO enrichment of the interactors. The GO analysis was performed in cytoscape using all the interactors from the Y2H screen. The yellow nodes are significantly represented $(p<0.05)$ and the white node represents the entire set. The color bar indicates the correction $p$-value for each categories, which was done by Benjamini \& Hochberg False Discovery Rate (FDR) correction. The area of a node is proportional to the number of genes (green numbers labeled above the nodes) in the test set annotated to the corresponding GO category. Arrows indicate the hierarchy of the categories. (B) Co-expression coefficient distribution of candidate and random pairs. The co-expression coefficient between the 67 pairs of baits and prey were calculated using the online software CressExpress (http://cressexpress.org/). The solid line indicates candidate protein pairs discovered here and the dotted line indicates random protein pairs. Student $t$-test was performed in SAS8.0 and the $p=2 \mathrm{E}-4$. (C) Core XLG interactome network. The 72 interactors from the Y2H screen plus additional candidates that have at least 2 edges are shown. The nodes with pink and yellow color indicate interactors identified here and blue nodes are taken from the BioGRID database and the literature (Wang et al., 2017). Pink nodes designate an interactor that has a positive co-expression coefficient, and yellow nodes have a negative co-efficient. Different edge colors represent the different interaction methods as indicated. 
containing 1779 arrays and included all the experimental results in our analyses. After the analyses, Pearson correlation coefficients and $p$-values were generated to evaluate the co-expression relationship between the two genes. The coexpression correlation coefficient ranged from -1 to +1 , with +1 indicating a perfect positive correlation and the $p$-value indicated the strength of the co-expression (Wei et al., 2006). The co-expression relationship between 4 of the 72 pairs was not found. The results showed 62 out of 68 (91.17\%) display significantly positive or negative correlation coefficient and 52 of them $(76.47 \%)$ had positive correlation. Figure 1B shows the distribution of the correlation coefficient of the 68 protein pairs from the interactome and 2000 random selected pairs. The randomly-selected gene pairs formed a normal distribution around a correlation coefficient of -0.1 . In contrast, the distribution of the candidate gene pairs was bimodal and right shifted with the maxima at 0.1 and 0.5 ). A Student $T$-test showed that the distribution of candidate gene pairs was significantly right-shifted from random pairs $(p=2 \mathrm{E}-4)$ indicating that the co-expression of the gene pairs is not random.

\section{XLG Partners Direct Subcellular Localization of XLG Proteins}

To ascertain the quality of the set of potential XLG interactors, 18 candidates were tested for XLG interaction in vivo using Bimolecular Fluorescence Complementation (BiFC) (Table 1, marked with $*)$. Eleven $(>60 \%)$ were confirmed by BiFC to interact with both XLG1 and XLG3 bait in vivo (Figures 2, 3). Supplementary Figure $\mathbf{S} 2$ provides the negative controls used in these assays. The interaction partner affects the localization. For example, At1g73030, which encodes an ESCRT-related protein that co-localizes to the plasma membrane and endosome (Tian et al., 2007; Spitzer et al., 2015) interacted with XLG1 and XLG3 in punctate structures (Figure 2A). At1g44170, encodes an aldehyde dehydrogenase induced by $\mathrm{ABA}$ and dehydration, and interacts with XLG1 and XLG3 on the plasma membrane (Figure 2B). SZF1 and SZF2 are two transcription factors that interact with XLG1 and XLG3 in the nucleus (Figure 3). This partner-dependent localization explains the inconsistencies in the literature (Ding et al., 2008; Heo et al., 2012; Chakravorty et al., 2015; Maruta et al., 2015; Wang et al., 2017).

\section{Core XLG Interactome}

An interactome network (Figure 1C) was constructed based on the interactors identified herein together with potential interactions assembled from the BioGRID interactome database (http://thebiogrid.org). Nodes were included based on the following rules. Yellow and pink nodes are proteins identified in the present study that interact with the indicated XLG protein noted by the corresponding edges. Yellow nodes are XLG-interacting proteins that are negatively correlated whereas pink nodes are positively correlated based on the co-expression analyses. Blue nodes are proteins from public data that have at least two edges.

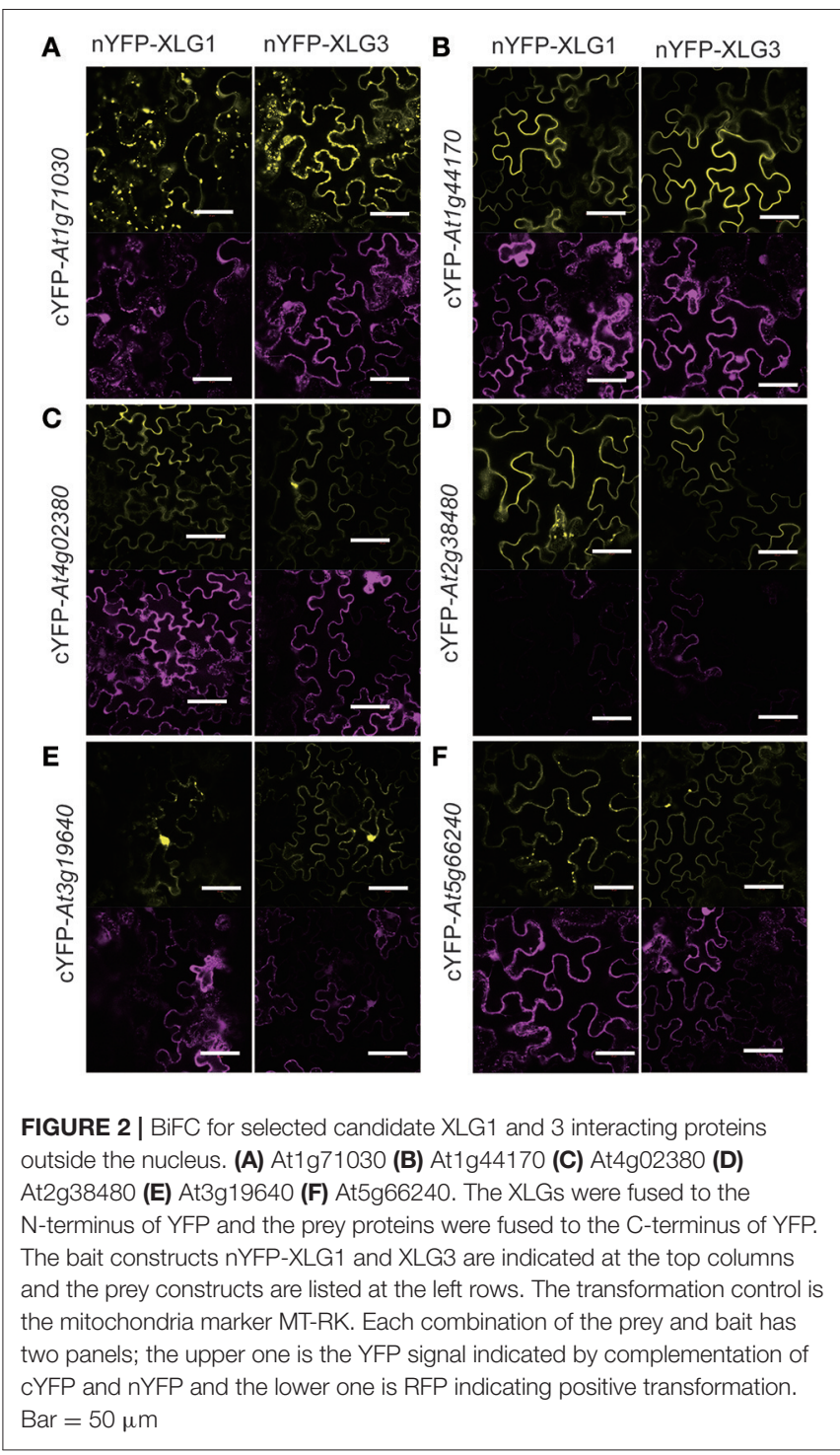

\section{XLGs Interact with SZFs and DCDs in the Nucleus}

As discussed above, some of the XLG protein-interactor pairs appeared to be nuclear localized. To determine the confidence level of the nuclear localization, we included the nuclear marker NLS-CFP and calculated the Spearman Rank Order coefficient (French et al., 2008) which measures the strength and direction of association between the nucleus marker NLS-CFP and the XLG interactors. As shown in Supplementary Figure S3, the box plot showed that the $3 / 4$ percentile line is above 0.2 and the median values for most is above 0.5 (exception is the XLG3 and SZF2 pair), indicating a strong positive correlation and therefore high confidence that the XLG interaction with the indicated partners mainly occurs in the nucleus.

DCD domain protein, also called N-rich protein (NRP) (Ludwig and Tenhaken, 2001), is induced during the hypersensitive reaction caused by microbial pathogen and involved in development and death (Tenhaken et al., 2005). 


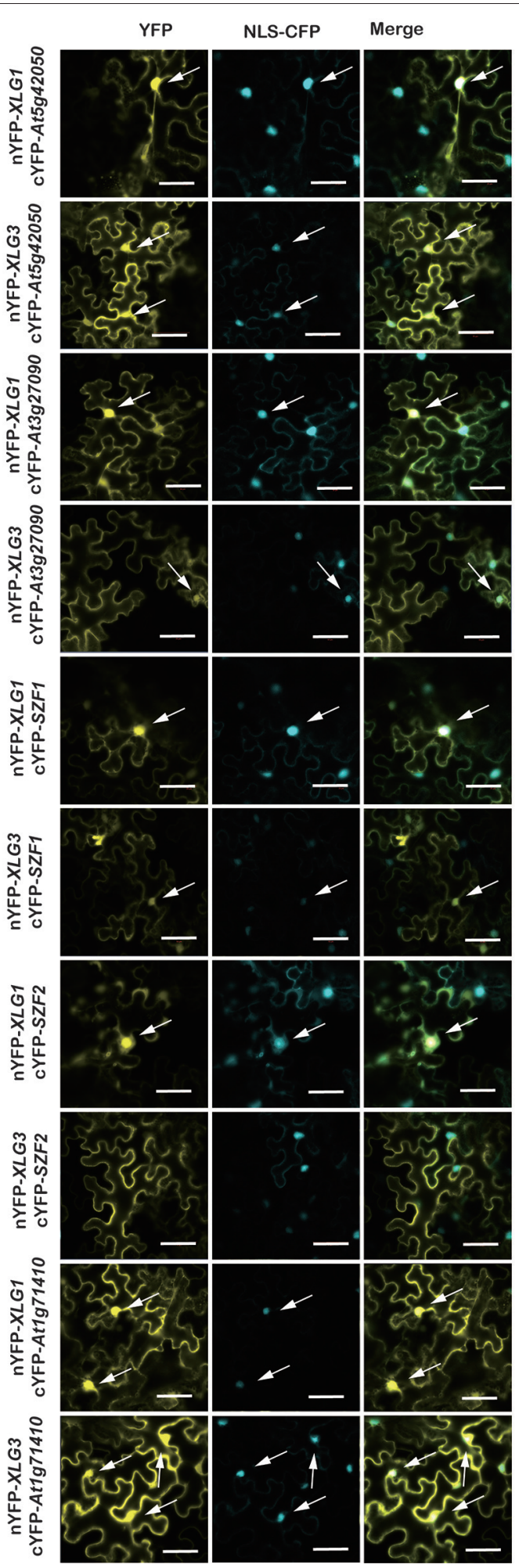

FIGURE 3 | BiFC for selected candidate XLG interacting proteins in the nucleus. The indicated XLG proteins fused to the $\mathrm{N}$-terminus of YFP with the prey proteins fused to the C-terminus of YFP is provided on the left rows. Positive transformation was confirmed by the nucleus marker NLS-CFP. Each combination of pairs shows three panels: the first column is the YFP signal

(Continued)
FIGURE 3 | Continued

indicated by fluorescence complementation of cYFP and nYFP, the second column is the CFP fluorescence of the nucleus marker, NLS-CFP (Nucleus Localization Signal CFP), and the last column is the merged images of the first two columns. Bar $=50 \mu \mathrm{m}$. The white arrows indicate a Spearman coefficient that is 0.75 or greater.

At5g42050, a DCD domain protein was reported to show signal translocated from cytosol to mitochondria during stress treatment (Hoepflinger et al., 2011). We did not observe this; our studies showed that At5g42050 is localized in the cytoplasm and nucleus (Supplementary Figure S3), which is consistent with our BiFC results (Figure 4). Moreover, subcellular localization of AtSZF1 and AtSZF2 in the protoplast was cytoplasmic and nuclear (Supplementary Figure S4), in contrast to published data that showed SZF1 is only nuclear localized in onion epidermal cells (Sun et al., 2007).

\section{SZF1 and 2 Are Induced by Salt in an XLG-Dependent Manner}

Previous reports showed that the expression of SZF1 and 2 is transiently induced by $\mathrm{NaCl}$ (Sun et al., 2007) but the concentration of $\mathrm{NaCl}$ they used was not provided and it is not known if the conditions they used extrapolate to conditions tested here. Therefore, we determined the kinetics and dosedependency for SZF1 and 2 gene expression induced by $\mathrm{NaCl}$ under our lab conditions.

Seven-day-old Arabidopsis seedlings were grown under dim light $\left(60-70 \mu \mathrm{Em}^{-2} \mathrm{~s}^{-1}\right)$ for the gene expression analyses. Seedlings were treated with either $150 \mathrm{mM}$ or $200 \mathrm{mM} \mathrm{NaCl}$ and sampled at $0,15 \mathrm{~min}, 30 \mathrm{~min}, 1,2$, and $4 \mathrm{~h}$. Treatment with $150 \mathrm{mM} \mathrm{NaCl}$ increased expression of SZF1 and SZF2 over 4 h (Figure 4A); with $200 \mathrm{mM} \mathrm{NaCl}$ treatment (Figure 4B), the expression level of SZF1 and SZF2 peaked at $2 \mathrm{~h}$. Note that this peak time is different than that published by Sun et al. (2007). A dose response was determined using $2 \mathrm{~h}$ as the endpoint. The expression level of SZF1 and SZF2 peaked at $200 \mathrm{mM}$ $\mathrm{NaCl}$ (Figure 4C). Having established the optimal $\mathrm{NaCl}$ dose for SZF gene expression and the timing of the peak expression under the conditions used here, we next determined if $S Z F$ gene expression is altered in the $\mathrm{G}$ protein mutants. The $S Z F$ gene expression level of the $\mathrm{G}$ protein mutants, agb1-2, rgs12, gpa1-3, xlg1/2/3 triple, and xlg1/2/3/gpa1-3 quadruple was tested at $200 \mathrm{mM} \mathrm{NaCl}$ for $2 \mathrm{~h}$ (with 5 biological replicates). $S Z F 1$ gene expression in the wild type increased 7 -fold whereas SZF1gene expression in the $a g b 1-2$ and $x l g 1 / 2 / 3$ triple mutants showed a lower response to the $\mathrm{NaCl}$ treatment (Figure 4E). The gpa1-3 single, xlg1/2/3/gpa1-3 triple, and rgs1-2 single mutants showed higher expression level in response to $\mathrm{NaCl}$ treatment. For $S Z F 2$, the gene expression level of the wild type increased 5 -fold, and just as for SZF1 expression, the expression level is lower in the agb1-2 single and $x \lg 1 / 2 / 3$ triple mutants and higher in the gpal-3 and rgs1-2 mutants (Figure 4F). We also tested the expression of genes encoding the salt induced DCD 


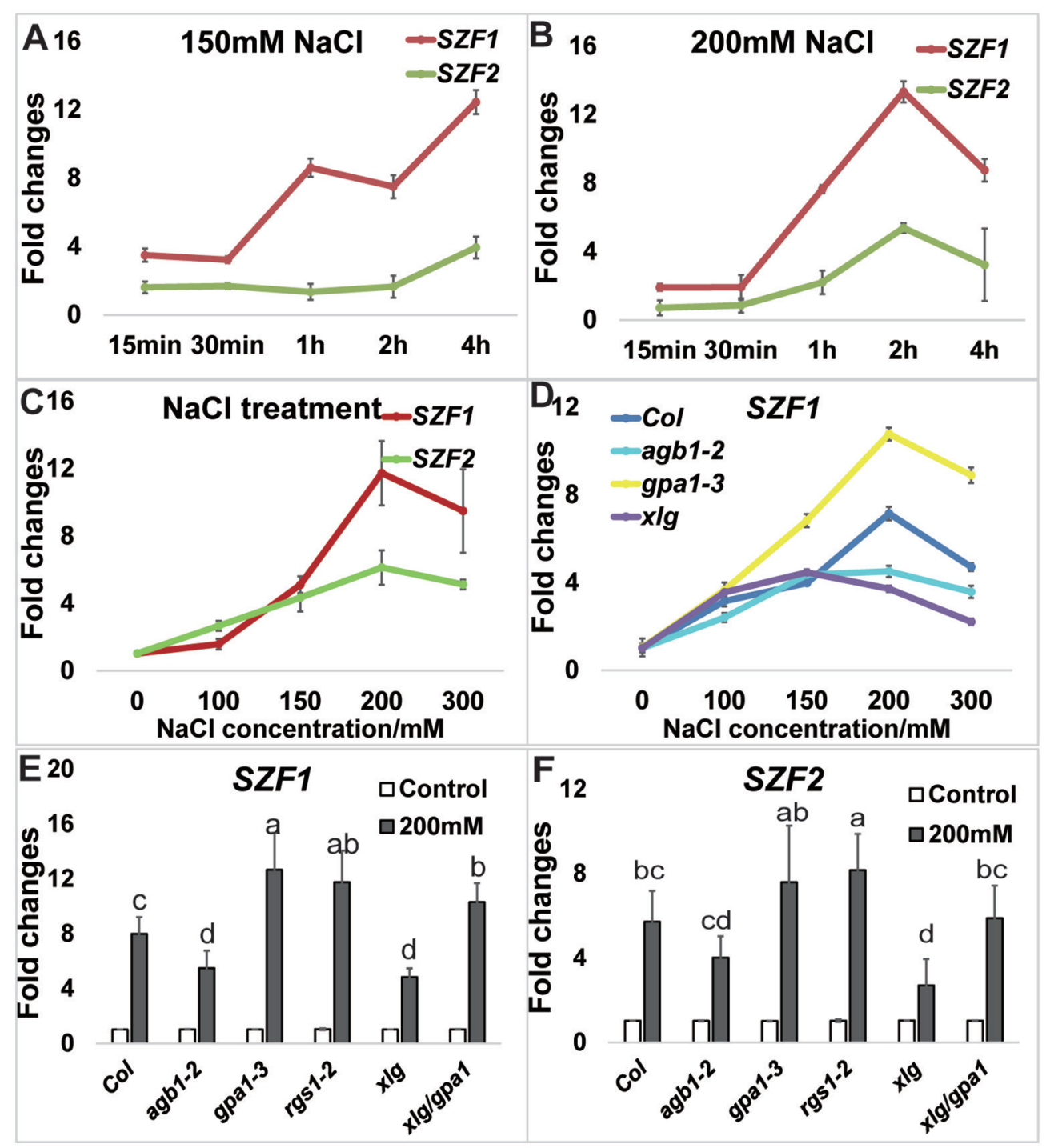

FIGURE 4 | NaCl-induced expression of SZFs. Seven-day-old Arabidopsis seedlings grown hydroponically in dim light room were used for the treatment. (A) The expression level of SZF1 and SZF2 in the time course of 0, 15, $30 \mathrm{~min}, 1,2$, and $4 \mathrm{~h}$ in the $150 \mathrm{mM}$ treatment as described in the Materials and Methods. (B) The expression level of SZF1 and SZF2 in the time course of 0 min-4 h after the $200 \mathrm{mM}$ treatment. (C) The expression level of SZF1 and SZF2 in the NaCl dose responses of 0, 100, 150, 200 mM. (D) The expression level of SZF1 and SZF2 in the NaCl dose responses of 0, 100, 150, 200 mM in the mutants of Col, agb1-2, gpa1-3, xlg1/2/3. (E,F) The expression level of SZF1 (E) and SZF2 (F) in response to $200 \mathrm{mM} \mathrm{NaCl}$ for $2 \mathrm{~h}$ between Col and G protein mutants [agb1-2, gpa1-3, rgs $1-2, x \lg 1 / x \lg 2 / x \lg 3$ triple (indicated $x \lg$ ) and $x \lg 1 / x \lg 2 / x \lg 3 / g p a 1-3$ quadruple (indicated $x \lg / g p a 1$ )]. ANOVA analysis was performed using SAS8.0 set at a $p=0.05$ with five biological replicates.

domain proteins At5g42050 (Hoepflinger et al., 2011), and found no differences between the $G$ protein mutants and the wild type (Supplementary Figure S5) suggesting that the reduction of the $\mathrm{NaCl}$-induced $S Z F$ gene expression in the $x \mathrm{lg}$ triple mutant is specific. Finally, salt resistance of the $G$ protein and SZF mutants were tested. The agb1-2 single, $x \lg$ triple and $x \lg 1 / x \lg 2 / x \lg 3 / g p a 1-3$ quadruple mutants were hypersensitive to salt stress under $150 \mathrm{mM} \mathrm{NaCl}$ treatment (Figure 5), consistent with previous reports (Colaneri et al., 2014; Yu and Assmann, 2015; Urano et al., 2016). The single mutants of szf1 and $s z f 2$ had wild type sensitivity to $\mathrm{NaCl}$ whereas the double szf1/2 mutants were hypersensitive (Figure 5) in agreement with previous findings (Sun et al., 2007). A NaCl sensitivity phenotype for the $s z f 1 / 2$ double mutants is consistent with our observation that gene expression of $S Z F 1 / 2$ is salt-inducible (Figure 4, Supplementary Table S3). Note that the reduced expression of $S Z F 1 / 2$ in the $x \lg 1 / 2 / 3 / g p a 1$ quadruple mutants was rescued to wildtype level by loss of the gpa1-3 null mutant (Figures 4E,F), whereas in the salt stress experiment, the growth of $x \lg 1 / 2 / 3 / g p a 1$ was not fully rescued by loss of GPA1, although it showed slight recovery. This is because at $150-200 \mathrm{mM} \mathrm{NaCl}$, the response is saturated. When retested at $75 \mathrm{mM} \mathrm{NaCl}$, loss of GPA1 


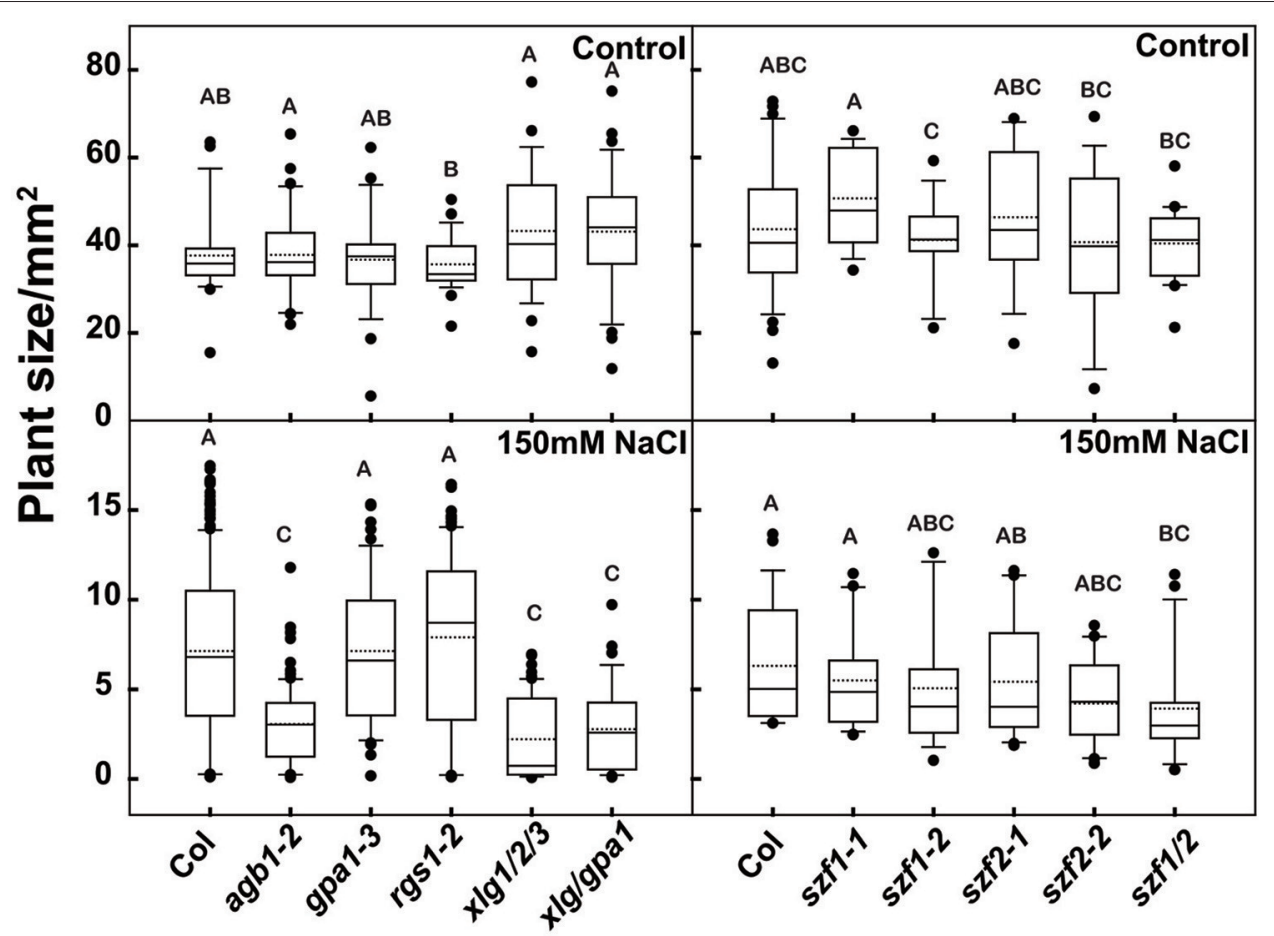

FIGURE 5 | Salt phenotypes of the G protein and szf mutants. Arabidopsis seedlings were grown horizontally on $1 / 4$ MS medium with $1 \%$ sucrose with or without 150 $\mathrm{mM} \mathrm{NaCl}$ under continuous dim light for 2 weeks, and the leaf area were measured to evaluate the growth status of the plants. The box plot indicates the distribution leaf area. The solid line in the box indicated the median and the dot line indicated the mean value. The bottom and the top of the box represented first and the third quartiles. The start and the end of the whiskers represented the maximum and minimum of the value. The dots represented the outliers. Different lowercases letter indicate significant differences $(p<0.05)$ between any two genotypes. The ANOVA analysis was performed using SAS8.0, $n \geq 24$.

fully rescued the salt hypersensitivity of $x \lg 1 / 2 / 3$ triple mutant (Supplementary Figure S6).

According to the salt stress phenotype data and the gene expression data, we propose a working model of the role of $\mathrm{G}$ protein signaling during salt stress (Figure 6). In this model, the RGS1 protein interacts with $\mathrm{G} \alpha$ to inhibit the $\mathrm{G} \alpha$ from releasing $\mathrm{G} \beta$ subunits, and G $\beta$ subunits interact with XLGs to regulate the gene expression of $S Z F 1$ and SZF2. The expression of SZF1 and SZF2 enhances the growth of plants under saline stress. We include a modulatory role for other regulators based on the literature.

\section{Newly-Identified Partners for XLG-Mediated Responses}

Among the 72 candidates, 5 are "in response to water deprivation," namely At2g41430 (ERD15), At4g15910 (DI21), At4g02380 (SAG21), At2g21620(RD2), and At1g44170 (ALDH3H1) (Supplementary Table S1). ERD15 (Early Response to Drought) is an attenuator of ABA responses and regulates stomatal aperture (Aalto et al., 2012). Overexpression of ERD15 sensitizes plants to drought stress (Kariola et al., 2006). Plant aldehyde dehydrogenases (ALDHs) contains 13 distinct families encoding aldehyde dehydrogenases which catalyze the oxidation of reactive aldehydes to their corresponding carboxylic acids using $\mathrm{NAD}(\mathrm{P})^{+}$as a cofactor (Kirch et al., 2001; Stiti et al.,

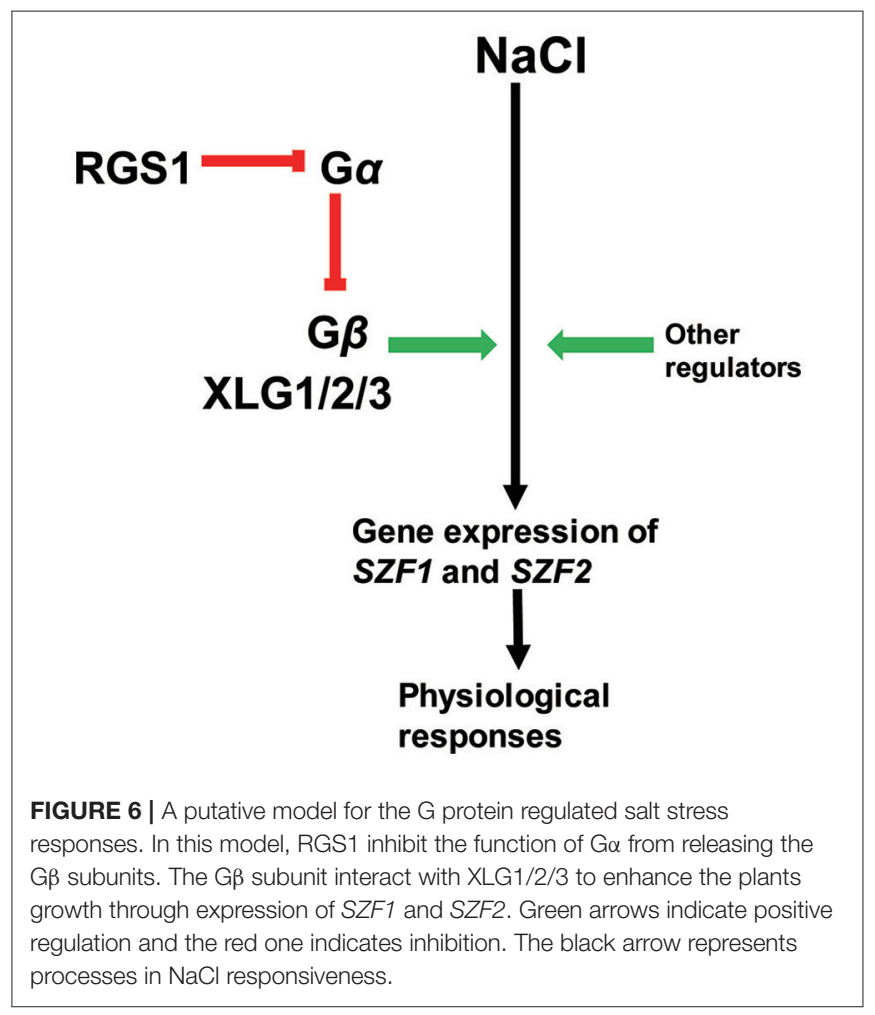


2011; Brocker et al., 2013). ABA, NaCl, and drought increases the expression level of the aldehyde dehydrogenase $3 \mathrm{H} 1$ gene (ALDH3H1) in the root (Missihoun et al., 2012). ALDH3H1 gene expression is important for long-term adaptation. G proteins regulate the drought stress response through multiple strategies. GPA1 regulates transpiration efficiency and stomatal density (Zhang et al., 2008; Nilson and Assmann, 2010). AGB1 is important for drought tolerance (Xu et al., 2015). AtRGS1 plays a role in ABA and drought tolerance (Chen et al., 2006). Phospholipase D (PLD) is involved in the osmotic stress response through hydrolysis of phosphatidic acid (PA), the ABA signaling pathway (Jacob et al., 1999) and the biosynthesis of proline (Thiery et al., 2004). PDL $\alpha 1$ interacts with GPA1 (Thiery et al., 2004) and AtRGS1 (Choudhury and Pandey, 2016), and the product of PLD $\alpha 1$, phosphatidic acid, may slightly inhibit the GAP activity of AtRGS1 (Choudhury and Pandey, 2017).

The data suggest that XLG is involved in trafficking. The interactors ESCRT (endosomal sorting complexes required for transport)-related CHARGED MULTIVESICULAR BODY PROTEIN/CHROMATIN MODIFYING PROTEIN1A (CHMP1A; At1g73030) and CHMP1B (At1g17730) proteins are essential for embryo and seedling development (Spitzer et al., 2009).

As shown in Figure 1C, PHR1 interacts with SPX1, which itself interacts with AtRGS1. SPX1 is an inhibitor of PHR1 (Puga et al., 2014). The phr1 (At4g28610) mutant is defective in the Pi starvation response (Rubio et al., 2001) and cooperates with another protein PHL1 (At5g29000) to regulate root hair development in response to phosphate starvation (Bustos et al., 2010). This information suggests that $G$ proteins play a part in phosphate sensing and regulation.

Annotation of "Cadmium Stress" ranks highest in the G protein interactome (Klopffleisch et al., 2011). In the present study on XLG interactors, cadmium stress also appeared. There are four genes annotated as response to cadmium, namely At2g01140, At3g03780 (MS2), At5g17920 (ATMS1), At3g60750 (Supplementary Table S1). A null mutation in the rice OsDEP1, encoding the gamma subunit of the G protein, confers cadmium stress on yeast cells and plants (Kunihiro et al., 2013). The $x \lg 1 / 2 / 3$ triple mutants and $a g b 1-2$ are hypersensitive to cadmium stress (Urano et al., 2016).

\section{Summary}

The number of studies on XLGs grew slowly since the first plant extra-large $G$ protein was reported (Lee and Assmann, 1999), however, in the last 2 years, interest in these atypical signal components has surged relatively (Chakravorty et al., 2015; Maruta et al., 2015; Liang et al., 2016; Urano et al., 2016; Wang et al., 2017). The general role for XLG proteins centers on stress responsiveness but we still lack a good understanding of the mechanism and while the subcellular localization has been reported, there has been conflicting results with no explanation. Our work provides a large set of stress-related proteins for future studies to test mechanism. We also provide an explanation of the conflicting reports on XLG subcellular localization by showing that the localization of the XLGs is dependent on the specific interacting partner.

\section{AUTHOR CONTRIBUTIONS}

YL designed experiments, collected the data, prepared the figures, and wrote the manuscript. AJ wrote the manuscript and YG and YL edited the manuscript. AJ managed the project. All authors read and approved the final manuscript.

\section{FUNDING}

This work was supported by grants from the NIGMS (R01GM065989) and NSF (MCB-0718202) to AJ. A grant (DE-FG02-05er15671) to AJ from the Division of Chemical Sciences, Geosciences, and Biosciences, Office of Basic Energy Sciences of the US Department of Energy supported technical assistance. Publication of this work was supported by grants from Innovative Research Team Plan of the Agriculture Ministry and Program of Northwest A\&F University (ZD2013011) to $\mathrm{YG}$.

\section{ACKNOWLEDGMENTS}

YL thanks the Chinese Scholarship Council (CSC) for a fellowship that enabled her to perform this research at The University of North Carolina at Chapel Hill. YL also thanks Xiaoyu Zhao for her assistance in the salt assay, Jing Yang for her assistance in every aspect of this project, and members of the JonesLab for helpful discussion.

\section{ASSURANCE}

The interactors described here will be deposited into the Arabidopsis G protein interactome upon acceptance for publication. Website: http://bioinfolab.unl.edu/emlab/Gsignal/ index.pl

\section{SUPPLEMENTARY MATERIAL}

The Supplementary Material for this article can be found online at: http://journal.frontiersin.org/article/10.3389/fpls.2017. 01015/full\#supplementary-material

Supplementary Figure S1 | Autoactivation test for the XLG1, XLG2 and XLG3 in yeast. Yeast AH109 transformed with XLG1-pAS2-1, XLG2-pAS2-1 and XLG3-pAS2-1 were grown on dropout (DO) medium -Trp (W) to confirm transformation and cell viability. Autoactivation was assayed on DO-Trp-His-Ade supplemented with the indicated concentrations of 3-AT (0-20mM).

Supplementary Figure S2 | Negative controls for the BiFC. In all assays, positive transformation was confirmed by the mitochondria marker MT-RK. The combination of bait constructs nYFP-XLG1 and XLG3 and the prey constructs were listed above the figures. Each combination of the prey and bait had two panels, the upper one was the YFP signal indicated the complementary of the cYFP and nYFP and the lower one was RFP which was transformation control. $\mathrm{Bar}=50 \mu \mathrm{m}$

Supplementary Figure S3 | Spearman Rank Order coefficients for nuclear localization. This coefficient is to examine the colocalization between the nucleus marker NLS-CFP and the yellow fluorescence. The range of the coefficient is from -1 , a strong negative correlation, to +1 , a strong positive correlation. The $p$-value above 0.195 (the spearman coefficient when, $p<0.05$, degree of freedom $=100$ ) is positive correlated. Box plots indicate the distribution of the coefficient and the number of the samples labeled in the figure. The solid line inside the box indicates 
the median and the dotted line indicates the mean value. The bottom and the top of the box represent first and third quartiles. The start and the end of the whiskers represented the maximum and minimum of the values. The dots represent the outliers.

Supplementary Figure S4 | Subcellular localization of SZF1, SZF2 and DCD protein At5g42050. Protoplasts were isolated from 5-week-old Arabidopsis Col and transformed with GFP-SZF1, GFP-SZF2 and GFP-At5g42050 in addition to the nucleus marker Histone-2B-RFP. The constructs (GFP-SZF1, GFP-SZF2 and GFP-At5g42050) are listed to the left of the images. Each construct has three panels from left to right, A, D and $\mathbf{G}$, GFP signal are the expression patterns of theindicated target proteins; (B, E, and $\mathbf{H})$, RFP signal is the nucleus signal; (C, F and $\mathbf{I})$, the merge images of GFP and RFP. Bar $=10 \mu \mathrm{m}$.

Supplementary Figure S5 | Salt-induced DCD domain protein At5g42050 gene expression. Seven-day-old Arabidopsis seedlings $\mathrm{Co}$ and $\mathrm{G}$ protein mutants (agb1-2, gpa1-3, rgs1-2, xlg1/xlg2/xlg3 and xlg1/xlg2/xlg3/gpa1-3) grown hydroponically in dim light room were treated with $200 \mathrm{mM} \mathrm{NaCl}$ for $2 \mathrm{~h}$. ANOVA analysis with SAS8.0, $p<0.05$, five biological replicates.

Supplementary Figure S6 | Salt phenotypes of the G protein under mild salt stress. Seedlings of the indicated genotypes were grown in 1/2 MS medium with or without $75 \mathrm{mM} \mathrm{NaCl}$ for 18 days. Box plot indicates the distribution leaf areas.

\section{REFERENCES}

Aalto, M. K., Helenius, E., Kariola, T., Pennanen, V., Heino, P., Horak, H., et al. (2012). ERD15-an attenuator of plant ABA responses and stomatal aperture. Plant Sci. 182, 19-28. doi: 10.1016/j.plantsci.2011.08.009

Bhardwaj, N., and Lu, H. (2009). Co-expression among constituents of a motif in the protein-protein interaction network. J. Bioinform. Comput. Biol. 7, 1-17. doi: 10.1142/S0219720009003959

Brocker, C., Vasiliou, M., Carpenter, S., Carpenter, C., Zhang, Y., Wang, X., et al. (2013). Aldehyde dehydrogenase (ALDH) superfamily in plants: gene nomenclature and comparative genomics. Planta 237, 189-210. doi: 10.1007/s00425-012-1749-0

Bustos, R., Castrillo, G., Linhares, F., Puga, M. I., Rubio, V., Perez-Perez, J., et al. (2010). A central regulatory system largely controls transcriptional activation and repression responses to phosphate starvation in Arabidopsis. PLoS Genet. 6:e1001102. doi: 10.1371/journal.pgen.1001102

Chakravorty, D., Gookin, T. E., Milner, M. J., Yu, Y., and Assmann, S. M. (2015). Extra-large G proteins expand the repertoire of subunits in arabidopsis heterotrimeric G protein signaling. Plant Physiol. 169, 512-529. doi: $10.1104 /$ pp.15.00251

Chakravorty, D., Trusov, Y., Zhang, W., Acharya, B. R., Sheahan, M. B., McCurdy, D. W., et al. (2011). An atypical heterotrimeric G-protein gamma-subunit is involved in guard cell $\mathrm{K}(+)$-channel regulation and morphological development in Arabidopsis thaliana. Plant J. 67, 840-851. doi: 10.1111/j.1365-313X.2011.04638.x

Chen, J.-G., Willard, F. S., Huang, J., Liang, J., Chasse, S. A., Jones, A. M., et al. (2003). A seven-transmembrane RGS protein that modulates plant cell proliferation. Science 301, 1728-1731. doi: 10.1126/science.1087790

Chen, Y., Ji, F., Xie, H., and Liang, J. (2006). Overexpression of the regulator of G-protein signalling protein enhances ABA-mediated inhibition of root elongation and drought tolerance in Arabidopsis. J. Exp. Bot. 57, 2101-2110. doi: $10.1093 /$ jxb/erj167

Choudhury, S., and Pandey, S. (2016). The role of PLDalphal in providing specificity to signal-response coupling by heterotrimeric G-protein components in Arabidopsis. Plant J. 86, 50-61. doi: 10.1111/tpj.13151

Choudhury, S. R., and Pandey, S. (2017). Phosphatidic acid binding inhibits RGS1 activity to affect specific signaling pathways in Arabidopsis. Plant J. 90, 466-477. doi: 10.1111/tpj.13503

Colaneri, A. C., Tunc-Ozdemir, M., Huang, J. P., and Jones, A. M. (2014). Growth attenuation under saline stress is mediated by the heterotrimeric $\mathrm{G}$ protein complex. BMC Plant Biol. 14:129 doi: 10.1186/1471-2229-14-129

Criekinge, W. V., and Beyaert, R. (1999). Yeast two-hybrid state of the art. Biol. Proced. Online 2, 1-38.
The solid line in the box indicates the median and the dot line indicates the mean value. The bottom and the top of the box represent first and third quartiles. The start and the end of the whiskers represent the maximum and minimum of the values. The dots represent the outliers. Different lowercases letter indicated significant differences $(p<0.05)$ between any two genotypes. The ANOVA analysis with SAS8.0, $n=24$.

Supplementary Table S1 | GO enrichment analysis of the interactors. This excel file provides the GO analysis results from the BiNGO. The $p<0.05$, and the correction $p$-value was performed by Benjamini \& Hochberg False Discovery Rate (FDR) correction.

Supplementary Table S2 | The primers used in this paper. Shown are the primers used for the indicated TOPO cloning and the qRT-PCR reactions.

Supplementary Table S3 | The quantitative fold changes for the real time PCR. Shown are the quantitative fold changes for the real time PCR in corresponding to Figures 4E,F and Figure S5. ANOVA analysis with SAS8.0, $p<0.05$, five biological replicates. The value indicates the standard error.

Supplementary Table S4 | The raw data for the $\mathrm{Y} 2 \mathrm{H}$. This table provides the raw data for the $\mathrm{Y} 2 \mathrm{H}$ without filtering the published artifacts. The known artifacts were in red.

Ding, L., Pandey, S., and Assmann, S. M. (2008). Arabidopsis extra-large G proteins (XLGs) regulate root morphogenesis. Plant J. 53, 248-263. doi: 10.1111/j.1365-313X.2007.03335.x

French, A. P., Mills, S., Swarup, R., Bennett, M. J., and Pridmore, T. P. (2008). Colocalization of fluorescent markers in confocal microscope images of plant cells. Nat. Protoc. 3, 619-628. doi: 10.1038/nprot.2008.31

Grigston, J. C., Osuna, D., Scheible, W. R., Liu, C., Stitt, M., and Jones, A. M. (2008). D-Glucose sensing by a plasma membrane regulator of $G$ signaling protein, AtRGS1. FEBS Lett. 582, 3577-3584. doi: 10.1016/j.febslet.2008.08.038

Hamm, H. E. (1998). The many faces of G protein signaling. J. Biol. Chem. 273, 669-672. doi: 10.1074/jbc.273.2.669

Heo, J. B., Sung, S., and Assmann, S. M. (2012). $\mathrm{Ca}^{2+}$-dependent GTPase, extra-large G protein 2 (XLG2), promotes activation of DNA-binding protein related to vernalization 1 (RTV1), leading to activation of floral integrator genes and early flowering in Arabidopsis. J. Biol. Chem. 287, 8242-8253. doi: 10.1074/jbc.M111.317412

Hoepflinger, M. C., Pieslinger, A. M., and Tenhaken, R. (2011). Investigations on N-rich protein (NRP) of Arabidopsis thaliana under different stress conditions. Plant Physiol. Biochem. 49, 293-302. doi: 10.1016/j.plaphy.2011.01.005

Jacob, T., Ritchie, S., Assmann, S. M., and Gilroy, S. (1999). Abscisic acid signal transduction in guard cells is mediated by phospholipase D activity. Proc. Natl. Acad. Sci. U.S.A. 96, 12192-12197. doi: 10.1073/pnas.96.21.12192

Jones, A. M., Ecker, J. R., and Chen, J. G. (2003). A reevaluation of the role of the heterotrimeric $\mathrm{G}$ protein in coupling light responses in Arabidopsis. Plant Physiol. 131, 1623-1627. doi: 10.1104/pp.102.017624

Kariola, T., Brader, G., Helenius, E., Li, J., Heino, P., and Palva, E. T. (2006). Early responsive to dehydration 15 , a negative regulator of abscisic acid responses in Arabidopsis. Plant Physiol. 142, 1559-1573. doi: 10.1104/pp.106.086223

Kirch, H.-H., Nair, A., and Bartels, D. (2001). Novel ABA- and dehydrationinducible aldehyde dehydrogenase genes isolated from resurrection plant Craterostigma plantagineum and Arabidopsis thaliana. Plant J. 28, 555-567. doi: 10.1046/j.1365-313X.2001.01176.x

Klopffleisch, K., Phan, N., Augustin, K., Bayne, R. S., Booker, K. S., Botella, J. R., et al. (2011). Arabidopsis G-protein interactome reveals connections to cell wall carbohydrates and morphogenesis. Mol. Syst. Biol. 7:532. doi: $10.1038 / \mathrm{msb} .2011 .66$

Kunihiro, S., Saito, T., Matsuda, T., Inoue, M., Kuramata, M., Taguchi-Shiobara, F., et al. (2013). Rice DEP1, encoding a highly cysteine-rich G protein gamma subunit, confers cadmium tolerance on yeast cells and plants. J. Exp. Bot. 64, 4517-4527. doi: 10.1093/jxb/ert267

Lee, Y. R., and Assmann, S. (1999). Arabidopsis thaliana 'extra-large GTP-binding protein' (AtXLG1) a new class of G-protein. Plant Mol. Biol. 40, 55-64. doi: 10.1023/A:1026483823176 
Li, L., Wright, S. J., Krystofova, S., Park, G., and Borkovich, K. A. (2007). Heterotrimeric $\mathrm{G}$ protein signaling in filamentous fungi. Annu. Rev. Microbiol. 61, 423-452. doi: 10.1146/annurev.micro.61.080706.093432

Liang, X., Ding, P., Lian, K., Wang, J., Ma, M., Li, L., et al. (2016). Arabidopsis heterotrimeric $\mathrm{G}$ proteins regulate immunity by directly coupling to the FLS2 receptor. Elife 5:e13568. doi: 10.7554/eLife.13568

Livak, K. J., and Schmittgen, T. D. (2001). Analysis of relative gene expression data using real-time quantitative PCR and the 2(-Delta Delta C(T)) Method. Methods 25, 402-408. doi: 10.1006/meth.2001.1262

Ludwig, A. A., and Tenhaken, R. (2001). A new cell wall located N-rich protein is strongly induced during the hypersensitive response in Glycine max L. Eur. J. Plant Pathol. 107, 323-336. doi: 10.1023/A:1011202225323

Maere, S., Heymans, K., and Kuiper, M. (2005). BiNGO: a cytoscape plugin to assess overrepresentation of gene ontology categories in biological networks. Bioinformatics 21, 3448-3449. doi: 10.1093/bioinformatics/bti551

Maruta, N., Trusov, Y., Brenya, E., Parekh, U., and Botella, J. R. (2015). Membranelocalized extra-large $\mathrm{G}$ proteins and $\mathrm{Gbg}$ of the heterotrimeric $\mathrm{G}$ proteins form functional complexes engaged in plant immunity in Arabidopsis. Plant Physiol. 167, 1004-1016. doi: 10.1104/pp.114.255703

Missihoun, T.D., Kirch, H. H., and Bartels, D. (2012). T-DNA insertion mutants reveal complex expression patterns of the aldehyde dehydrogenase $3 \mathrm{H} 1$ locus in Arabidopsis thaliana. J. Exp. Bot. 63, 3885-3898. doi: 10.1093/jxb/ers081

Nilson, S. E., and Assmann, S. M. (2010). The alpha-subunit of the Arabidopsis heterotrimeric $\mathrm{G}$ protein, GPA1, is a regulator of transpiration efficiency. Plant Physiol. 152, 2067-2077. doi: 10.1104/pp.109.148262

Oldham, W. M., and Hamm, H. E. (2008). Heterotrimeric G protein activation by G-protein-coupled receptors. Nat. Rev. Mol. Cell Biol. 9, 60-71. doi: 10.1038/nrm2299

Pandey, S., Chen, J. G., Jones, A. M., and Assmann, S. M. (2006). Gprotein complex mutants are hypersensitive to abscisic acid regulation of germination and postgermination development. Plant Physiol. 141, 243-256. doi: $10.1104 /$ pp.106.079038

Puga, M. I., Mateos, I., Charukesi, R., Wang, Z., Franco-Zorrilla, J. M., De Lorenzo, L., et al. (2014). SPX1 is a phosphate-dependent inhibitor of Phosphate Starvation Response 1 in Arabidopsis. Proc. Natl. Acad. Sci. U.S.A. 111, 14947-14952. doi: 10.1073/pnas.1404654111

Rubio, V., Linhares, F., Solano, R., Martín, A. C., Iglesias, J., Leyva, A., et al. (2001). A conserved MYB transcription factor involved in phosphate starvation signaling both in vascular plants and in unicellular algae. Genes Dev. 15, 2122-2133. doi: 10.1101/gad.204401

Spitzer, C., Li, F., Buono, R., Roschzttardtz, H., Chung, T., Zhang, M., et al. (2015). The endosomal protein CHARGED MULTIVESICULAR BODY PROTEIN1 regulates the autophagic turnover of plastids in Arabidopsis. Plant Cell 27, 391-402. doi: 10.1105/tpc.114.135939

Spitzer, C., Reyes, F. C., Buono, R., Sliwinski, M. K., Haas, T. J., and Otegui, M. S. (2009). The ESCRT-related CHMP1A and B proteins mediate multivesicular body sorting of auxin carriers in Arabidopsis and are required for plant development. Plant Cell 21, 749-766. doi: 10.1105/tpc.108.064865

Stiti, N., Missihoun, T. D., Kotchoni, S. O., Kirch, H. H., and Bartels, D. (2011). Aldehyde dehydrogenases in Arabidopsis thaliana: biochemical requirements, metabolic pathways, and functional analysis. Front. Plant Sci. 2:65. doi: 10.3389/fpls.2011.00065

Sun, J., Jiang, H., Xu, Y., Li, H., Wu, X., Xie, Q., et al. (2007). The CCCH-type zinc finger proteins AtSZF1 and AtSZF2 regulate salt stress responses in Arabidopsis. Plant Cell Physiol. 48, 1148-1158. doi: 10.1093/pcp/ pcm088

Tenhaken, R., Doerks, T., and Bork, P. (2005). DCD - a novel plant specific domain in proteins involved in development and programmed cell death. BMC Bioinformatics 6:169. doi: 10.1186/1471-2105-6-169

Thiery, L., Leprince, A. S., Lefebvre, D., Ghars, M. A., Debarbieux, E., and Savoure, A. (2004). Phospholipase D is a negative regulator of proline biosynthesis in Arabidopsis thaliana. J. Biol. Chem. 279, 14812-14818. doi: 10.1074/jbc.M308456200

Tian, Q., Olsen, L., Sun, B., Lid, S. E., Brown, R. C., Lemmon, B. E., et al. (2007). Subcellular localization and functional domain studies of DEFECTIVE KERNEL1 in maize and Arabidopsis suggest a model for aleurone cell fate specification involving CRINKLY4 and SUPERNUMERARY ALEURONE LAYER1. Plant Cell 19, 3127-3145. doi: 10.1105/tpc.106.048868

Tunc-Ozdemir, M., Fu, Y., and Jones, A. M. (2016). Cautions in measuring in vivo interactions Using FRET and BiFC in Nicotiana benthamiana. Methods Mol. Biol. 1363, 155-174. doi: 10.1007/978-1-4939-3115-6_13

Ullah, H., Chen, J. G., Temple, B., Boyes, D. C., Alonso, J. M., Davis, K. R., et al. (2003). The beta-subunit of the arabidopsis $\mathrm{G}$ protein negatively regulates auxin-induced cell division and affects multiple developmental processes. Plant Cell Online 15, 393-409. doi: 10.1105/tpc.006148

Urano, D., Chen, J. G., Botella, J. R., and Jones, A. M. (2013). Heterotrimeric $\mathrm{G}$ protein signalling in the plant kingdom. Open Biol. 3:120186. doi: $10.1098 /$ rsob.120186

Urano, D., Jones, J. C., Wang, H., Matthews, M., Bradford, W., Bennetzen, J. L., et al. (2012). G protein activation without a GEF in the plant kingdom. PLoS Genet. 8:e1002756. doi: 10.1371/journal.pgen.1002756

Urano, D., Maruta, N., Trusov, Y., Stoian, R., Wu, Q., Liang, Y., et al. (2016). Saltational evolution of the heterotrimeric $\mathrm{G}$ protein signaling mechanisms in the plant kingdom. Sci. Signal. 9, ra93. doi: 10.1126/scisignal.aaf9558

Venkatesan, K., Rual, J. F., Vazquez, A., Stelzl, U., Lemmens, I., HirozaneKishikawa, T., et al. (2009). An empirical framework for binary interactome mapping. Nat. Methods 6, 83-90. doi: 10.1038/nmeth.1280

Wang, Y., Wu, Y., Yu, B., Yin, Z., and Xia, Y. (2017). Extra-large G proteins interact with E3 ligases PUB4 and PUB2 and function in cytokinin and developmental processes. Plant Physiol. 173, 1235-1246. doi: 10.1104/pp.16.00816

Wei, H., Persson, S., Mehta, T., Srinivasasainagendra, V., Chen, L., Page, G. P., et al. (2006). Transcriptional coordination of the metabolic network in Arabidopsis. Plant Physiol. 142, 762-774. doi: 10.1104/pp.106.080358

Wettschureck, N. (2005). Mammalian G proteins and their cell type specific functions. Physiol. Rev. 85, 1159-1204. doi: 10.1152/physrev.00003.2005

Wolfenstetter, S., Chakravorty, D., Kula, R., Urano, D., Trusov, Y., Sheahan, M. B., et al. (2015). Evidence for an unusual transmembrane configuration of AGG3, a Class C G $\gamma$ Subunit, of Arabidopsis. Plant J. 81, 388-398. doi: 10.1111/tpj.12732

Xu, D. B., Chen, M., Ma, Y. N., Xu, Z. S., Li, L. C., Chen, Y. F., et al. (2015). A Gprotein beta subunit, AGB1, negatively regulates the ABA response and drought tolerance by down-regulating AtMPK6-related pathway in Arabidopsis. PLoS ONE 10:e0116385. doi: 10.1371/journal.pone.0116385

Yoo, S. D., Cho, Y. H., and Sheen, J. (2007). Arabidopsis mesophyll protoplasts: a versatile cell system for transient gene expression analysis. Nat. Protoc. 2, 1565-1572. doi: 10.1038/nprot.2007.199

Yu, Y., and Assmann, S. M. (2015). The heterotrimeric G-protein beta subunit, AGB1, plays multiple roles in the Arabidopsis salinity response. Plant Cell Environ. 38, 2143-2156. doi: 10.1111/pce.12542

Zhang, L., Hu, G., Cheng, Y., and Huang, J. (2008). Heterotrimeric G protein alpha and beta subunits antagonistically modulate stomatal density in Arabidopsis thaliana. Dev. Biol. 324, 68-75. doi: 10.1016/j.ydbio.2008.09.008

Conflict of Interest Statement: The authors declare that the research was conducted in the absence of any commercial or financial relationships that could be construed as a potential conflict of interest.

Copyright (c) 2017 Liang, Gao and Jones. This is an open-access article distributed under the terms of the Creative Commons Attribution License (CC BY). The use, distribution or reproduction in other forums is permitted, provided the original author(s) or licensor are credited and that the original publication in this journal is cited, in accordance with accepted academic practice. No use, distribution or reproduction is permitted which does not comply with these terms. 